\title{
Cotton-type collagen insertion at mediastinoscopy for easier node dissection after induction chemoradiotherapy for lung cancer
}

\author{
Kenichi Okubo, MD, Jun Isobe, MD, Toshihiko Sato, MD, and Yoichiro Ueno, MD, Gifu, Japan
}

I nduction chemoradiotherapy followed by anatomical resection is a current therapeutic strategy for non-small cell lung cancer with mediastinal node involvement. However, mediastinal node dissection after chemoradiotherapy is technically difficult because of the severe adhesion and fibrosis caused by the therapy. We describe a novel technique to make the node dissection easier after induction chemoradiotherapy.

\section{Clinical Summary}

Twenty-six consecutive patients with non-small cell lung cancer with mediastinal node metastasis underwent staging mediastinoscopy from 1998 to June 2002. Mediastinal lymph nodes were excised through a cervical approach under videoendoscopic view. ${ }^{1}$ At the end of mediastinoscopy, cotton-type collagen (Emistat; Nihon-Zoki, Osaka, Japan) at 1 to $2 \mathrm{~g}$ was inserted anterior and bilateral to the trachea with forceps (Figure 1). Induction chemoradiotherapy, consisting of concurrent use of platinum-based chemotherapy and hyperfractionated accelerated radiotherapy totaling 30 to $42 \mathrm{~Gy}$, was then administered. Anatomic resection with node dissection was planned for 3 or 4 weeks after the last chemotherapy administration.

At thoracotomy mediastinal nodes were sclerotic and fibrotic, with severe adhesion to the connective tissue around the trachea as a result of the induction chemoradiotherapy. The connective tissue was also sclerotic and organized, with scar formation. However, the collagen remained unabsorbed between the trachea and mediastinal nodes. Mediastinal node dissection was completed with removal of mediastinal tissues lateral and anterior to the collagen. The collagen was also removed to confirm that no lymph nodes were left around the trachea. Node dissection was easily and safely accomplished without injury to the trachea or great vessels. No adverse effects from the collagen insertion have been seen in any patients.

\footnotetext{
From the Department of General Thoracic Surgery, Gifu National Hospital, Gifu, Japan.

Received for publication Oct 17, 2003; accepted for publication Dec 15, 2003.

Address for reprints: Kenichi Okubo, MD, General Thoracic Surgery, Gifu National Hospital, Hinohigashi 5-1-1, Gifu 500-8718, Japan (E-mail: okubo@gifu.hosp.go.jp).

J Thorac Cardiovasc Surg 2004;127:1532-3

$0022-5223 / \$ 30.00$

Copyright $\odot 2004$ by The American Association for Thoracic Surgery

doi:10.1016/j.jtcvs.2003.12.027
}
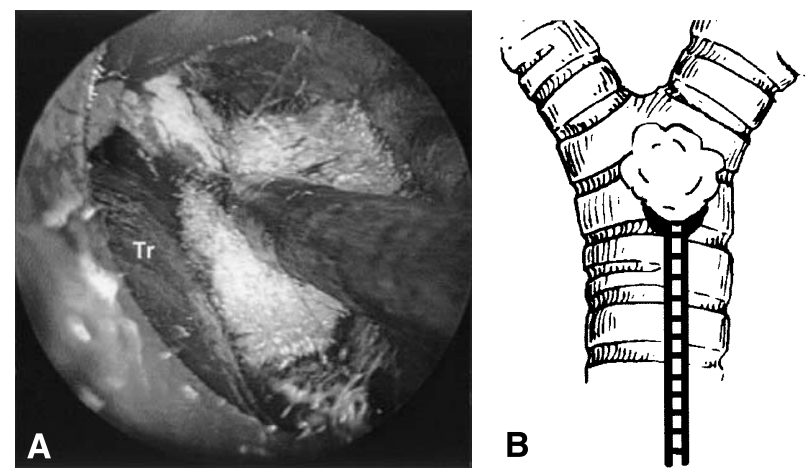

Figure 1. A, Mediastinoscopic view of cotton-type collagen insertion into anterior and lateral side of trachea (Tr). B, Schema of collagen insertion with forceps.

\section{Discussion}

Locally advanced non-small cell lung cancer that involves mediastinal lymph nodes is currently treated with induction therapy followed by anatomic resection. ${ }^{2,3}$ Operative mortality and morbidity are considered to be higher after chemoradiotherapy than without preoperative therapy. Mediastinal node dissection is technically difficult after chemoradiotherapy because of sclerotic and fibrotic change of both nodes and mediastinal tissues with severe adhesion to the trachea, as well as a postsurgical effect from mediastinoscopy. Because some mediastinal nodes were originally involved in this stage of lung cancer, node dissection should be complete to remove all possible cancer cells for curative intent. Attention should be paid to preventing impairment of the trachea by excessively deep dissection.

Cotton-type collagen (Emistat) is an absorbable topical hemostat produced by spinning atelocollagen derived from bovine corium, which is purified for medical use into absorbable form and then chemically cross-linked with polyepoxy compound. ${ }^{4}$ Atelocollagen is prepared by solubilizing calf corium by proteolytic enzyme digestion and subsequently removing major antigenic sites. The cotton-type microfibrillar form absorbs blood into interspace, where platelets adhere and aggregate to achieve hemostasis.

We inserted this collagen into the space between trachea and mediastinal nodes at staging mediastinoscopy in patients with mediastinal node-involved lung cancer. All the patients received induction chemoradiotherapy. Although we changed the chemoradiation program during the study period from cisplatin, 5-fluorouracil, and vindesine with total $30 \mathrm{~Gy}$ of irradiation to carboplatin and paclitaxel with total 42 Gy of irradiation, the duration from mediastinoscopy to thoracotomy was consistently 7 to 10 weeks. At thoracotomy, the collagen was found in all cases to be unabsorbed, keeping the mediastinal tissues away from the trachea. The substance 
appeared to indicate the dissection plane around the trachea. Cottontype collagen insertion thus can help to make mediastinal node dissection easier after induction chemoradiotherapy.

\section{References}

1. American Thoracic Society. Clinical staging of primary lung cancer. Am Rev Respir Dis. 1983;127:659-64.

2. Eberhardt W, Wilke H, Stamatis G, Stuschke M, Harstrick A, Menker
H, et al. Preoperative chemotherapy followed by concurrent chemoradiation therapy based on hyperfractionated accelerated radiotherapy and definitive surgery in locally advanced non-small-cell lung cancer: mature results of a phase II trial. J Clin Oncol. 1998;16:622-34.

3. Mathisen DJ, Wain JC, Wright C, Choi N, Carey R, Hilgenberg A, et al. Assessment of preoperative accelerated radiotherapy and chemotherapy in stage IIIA (N2) non-small-cell lung cancer. $J$ Thorac Cardiovasc Surg. 1996;111:123-33.

4. Kodaira K, Miyata T, Furuse M, Noishiki Y. Characterization of collagenous materials crosslinked by polyepoxy compounds. Jpn J Artif Organs. 1986;15:239-42. 